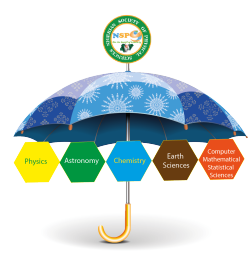

\title{
Modeling of Self Potential (SP) Anomalies over a Polarized Rod with Finite Depth Extents
}

\author{
T. S. Fagbemigun ${ }^{\mathrm{a}, *}$, M. O. Olorunfemi ${ }^{\mathrm{b}}$, S. A. Wahab ${ }^{\mathrm{c}}$ \\ ${ }^{a}$ Department of Geophysics, Federal University, Oye-Ekiti, Nigeria \\ ${ }^{b}$ Department of Geology, Obafemi Awolowo University, Ile Ife, Nigeria \\ ${ }^{c}$ Department of Applied Geophysics, Federal University of Technology, Akure, Nigeria
}

\begin{abstract}
Modeling is a powerful tool used by Geoscientists to provide pre-knowledge about the expectations of any geophysical field measurements. This study generates Self Potential (SP) anomalies over a typical dyke-like structure to observe the influence of depth of burial and dip on SP anomalies. A computer program was developed from the potential distribution equation of an inclined polarized rod with limited depth extent using Visual Basic (VB) programming language to produce synthetic data for potential distribution. The potential distribution data were used to generate theoretical SP anomaly curves for a polarized rod for varying depth of burial and dip. Twenty SP anomaly curves were generated with different dip values and depth of burial and from these curves superimposed curves were also generated. The anomalies were analyzed for the effect of depth of burial and attitude or dip. The SP anomaly curves generated show that increase in depth of burial causes reduction in the peak negative amplitude of SP anomaly curves. For inclined polarized rod at relatively shallow depth $(<2.0 \mathrm{~m})$, the peak negative amplitude remains virtually the same with a positive shoulder over the down dip side of the target. Also as the dip angle decreases from $90^{\circ}$ for fixed depth of burial, the anomaly curves become asymmetrical. At $\theta^{\circ}$, the distance between the peak negative and peak positive amplitude of the anomaly curve is equal to the linear extent of the rod. Therefore, this study shows that depth of burial inversely influences the amplitude of self potential (SP) anomalies while dip angle affects the form or symmetry of anomaly curves.
\end{abstract}

Keywords: Modeling, self potential, polarized rod, geologic dip, depth of burial

\section{Article History :}

Received: 15 April 2019

Received in revised form: 20 May 2019

Accepted for publication: 21 May 2019

Published: 31 May, 2019

(C)2019 Journal of the Nigerian Society of Physical Sciences. All rights reserved. Communicated by: O. J. Abimbola

\section{Introduction}

The pre-knowledge of the expectation on the field is very essential for any geophysical investigations and in turn, it serves as quality control on interpretation mindset of the geophysicist involved. In lieu of this, modeling or simulation of geophysicalrelated problems has become a vital tool in geophysics and this technique has allowed Geoscientists to come up with synthetic

${ }^{*}$ Corresponding author tel. no: +2348066358839

Email address: tsf agbemigun@gmail .com (T. S. Fagbemigun ) solutions against any related challenges on the field [1]. Numerical simulation of geometric source model involving the Self Potential (SP) method can yield valuable information related to the field data $[2,3,4]$. This aspect of geophysics enables the generation of theoretical anomalies over geologic structures which can be encountered on the field such as dykes, channels, sandlens and faults. Hence, such theoretical anomalies can aid our understanding of field anomalies and the interpretation of same $[5,6]$.

SP is one of the geophysical methods that makes use of natural electrical sources to study earths subsurface or for surface 
exploration. The SP method has found several applications in various areas of science and engineering such as mineral exploration [7], well-logging [8, 9], engineering [10, 11, 12], agricultural sciences $[13,14]$, environmental studies $[15,16,17]$.

This study aims to generate SP anomalies over a typical dyke-like feature for different depth extent and attitude (dip) as a means of investigating the influence of depth of burial and attitude on SP anomalies.

\section{Methodology}

Equation 1 shows the basic equation for potential distribution [18]:

$$
V= \pm q\left[\frac{1}{r_{1}}-\frac{1}{r_{2}}\right]
$$

here $V$ is the potential distribution around the object, $r_{1}$ is the distance from the point $P$ to the top of the rod, $r_{2}$ is the distance from the point $P$ to the bottom of the rod and $\pm q$ is the charge at either end of the rod (Figure 1). However, from Figure 1

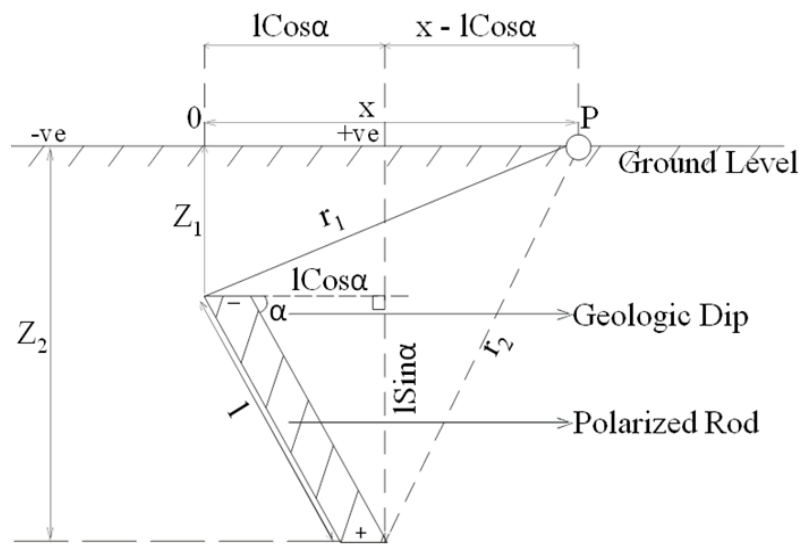

Figure 1: Diagrammatic Representation of Geometric Model of Self Potential for a Polarized Rod [18].

$$
\begin{gathered}
r_{1}=\left(x^{2}+Z_{1}^{2}\right)^{\frac{1}{2}}, \\
r_{2}=\left(Z_{2}^{2}+(x-l \cos \alpha)^{2}\right)^{\frac{1}{2}} .
\end{gathered}
$$

Where $\alpha$ is the geologic dip or attitude; $l$ is the length or depth extent; $Z_{1}$ is the depth of burial; $Z_{2}$ is the depth to the bottom of the rod from the ground level; and $x$ is the distance from the centre $(O)$ to observation point. Also from Figure 1:

$$
Z_{2}=Z_{1}+l \sin \alpha
$$

Therefore, substituting equations 2 and 3 into equation 1 , we get:

$$
V= \pm q\left[\frac{1}{\left(x^{2}+Z_{1}^{2}\right)^{\frac{1}{2}}}-\frac{1}{\left(Z_{2}^{2}+(x-l \cos \alpha)^{2}\right)^{\frac{1}{2}}}\right] .
$$

Also, substituting equation 4 into equation 5, we get:

$$
V= \pm q\left[\frac{1}{\left(x^{2}+Z_{1}^{2}\right)^{\frac{1}{2}}}-\frac{1}{\left(\left(Z_{1}+l \sin \alpha\right)^{2}+(x-l \cos \alpha)^{2}\right)^{\frac{1}{2}}}\right] .
$$

The parameters in equation 6 were considered in generating charge of the rod, depth of burial, geologic dip, length of the rod, depth to the bottom of the rod and distance in order for the theoretical potential distribution data generated to be concise and accurate. Visual Basic (VB) version 6.0 program was used for this study. Potential distribution response was generated at $2 m$ interval and the polarized rod was inclined at different attitudes and depths of burial. SP profiles were generated for the potential distribution values in $\operatorname{milliVolt}(\mathrm{mV})$ by plotting it against distance (in metre) from the observation point. Interpretation was solely based on visualization of amplitude pattern of the SP profiles (qualitative interpretation).

\section{Results and Discussion}

Twenty (20) SP anomaly curves were generated with different dips/attitudes $\left(0^{\circ}, 30^{\circ}, 60^{\circ}\right.$ and $\left.90^{\circ}\right)$ and depths of burial $(0.5 \mathrm{~m}, 2 \mathrm{~m}, 5 \mathrm{~m}, 10 \mathrm{~m}$ and $20 \mathrm{~m})$. We also generated six (6) superimposed SP anomaly curves for same depth of burial but different dips and six (6) superimposed SP anomaly curves for same geologic dip but different depths of burial. The anomalies were analyzed for the effect of depth of burial and attitude on the amplitude and symmetry of SP anomaly curves. Figures 2 and $3\left(0^{\circ}\right.$ and $\left.30^{\circ} \mathrm{dip}\right)$ are replica of each other, except for the difference in the values of points at which they inflected. It is observed that, as the geologic dip increases, the geometry of the curves turned to be cone-like. At points of inflection, values of SP decrease with the increase in depth of burial. For a polarized rod with $0^{\circ}$, the inflexion points of the anomaly curves are located at the middle of the rod (Figure 2). The result of the study by [19] validates this, as their investigation over dykelike structure gave birth to gradual increase to SP values over the target. 


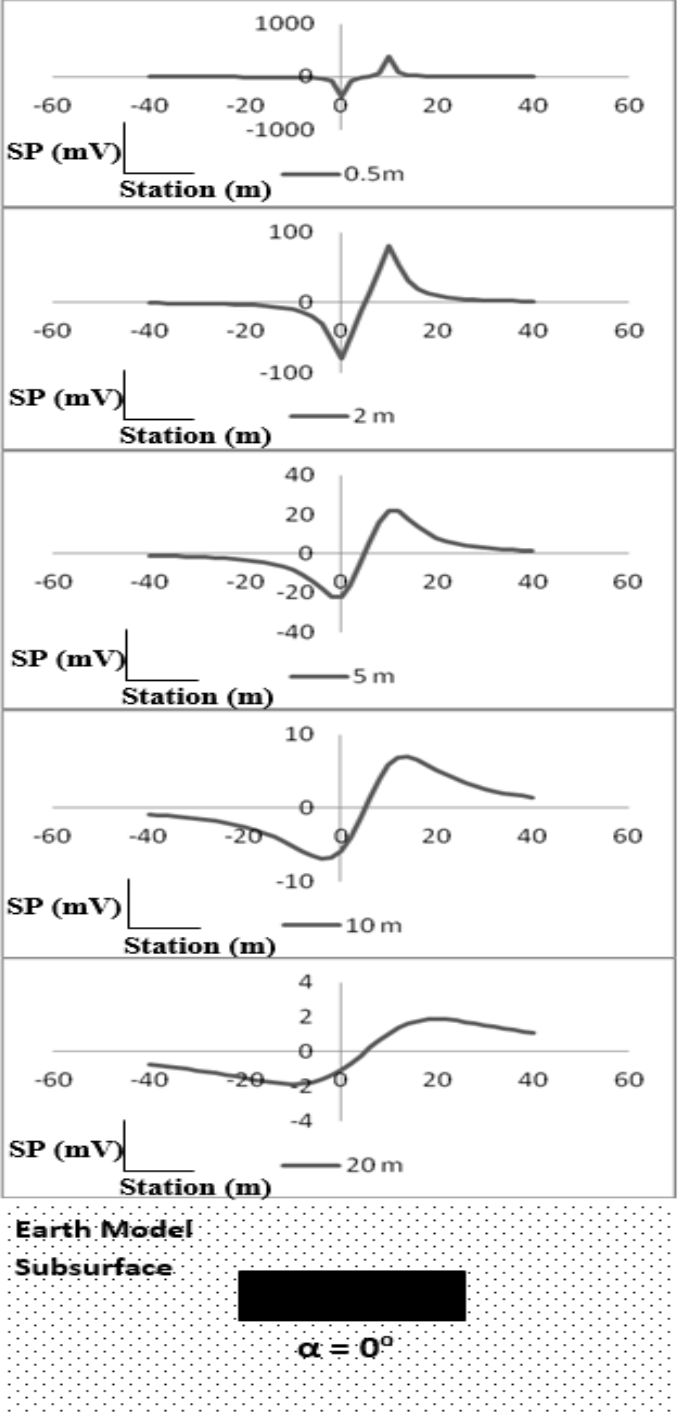

Figure 2: SP Profiles for $0^{\circ}$ Geologic Dip.

At relatively shallow depth $(<2.0 \mathrm{~m})$, the peak negative amplitude remains virtually the same with the shoulder over the down dip side of the target (Figures 10 - 11). The peak positive amplitude shoulder is therefore, maximum on the down dip side.

Figures 4 and 5 display the SP anomaly curves for $60^{\circ}$ and $90^{\circ}$ dips. These curves are characterized with negative peak amplitudes. The negative peak at lower depth of burial is sharp compared to the deeper depth of burial. The maximum and minimum negative SP values are $-3.2 \mathrm{mV}$ and $-380 \mathrm{mV}$ respectively. In all the anomalies generated except for dip angle of $0^{\circ}$, the top of the target is located beneath a peak negative amplitude SP (Figures 3 - 5). The SP anomalies for a vertically dipping rod is symmetrical about the top of the rod while the anomalies become asymmetrical as the dip angle is decreased from $90^{\circ}$ (Figures 2 - 5). The study by [3] corroborates with the results of this study in terms of symmetrical nature and amplitude of the SP anomaly curves.

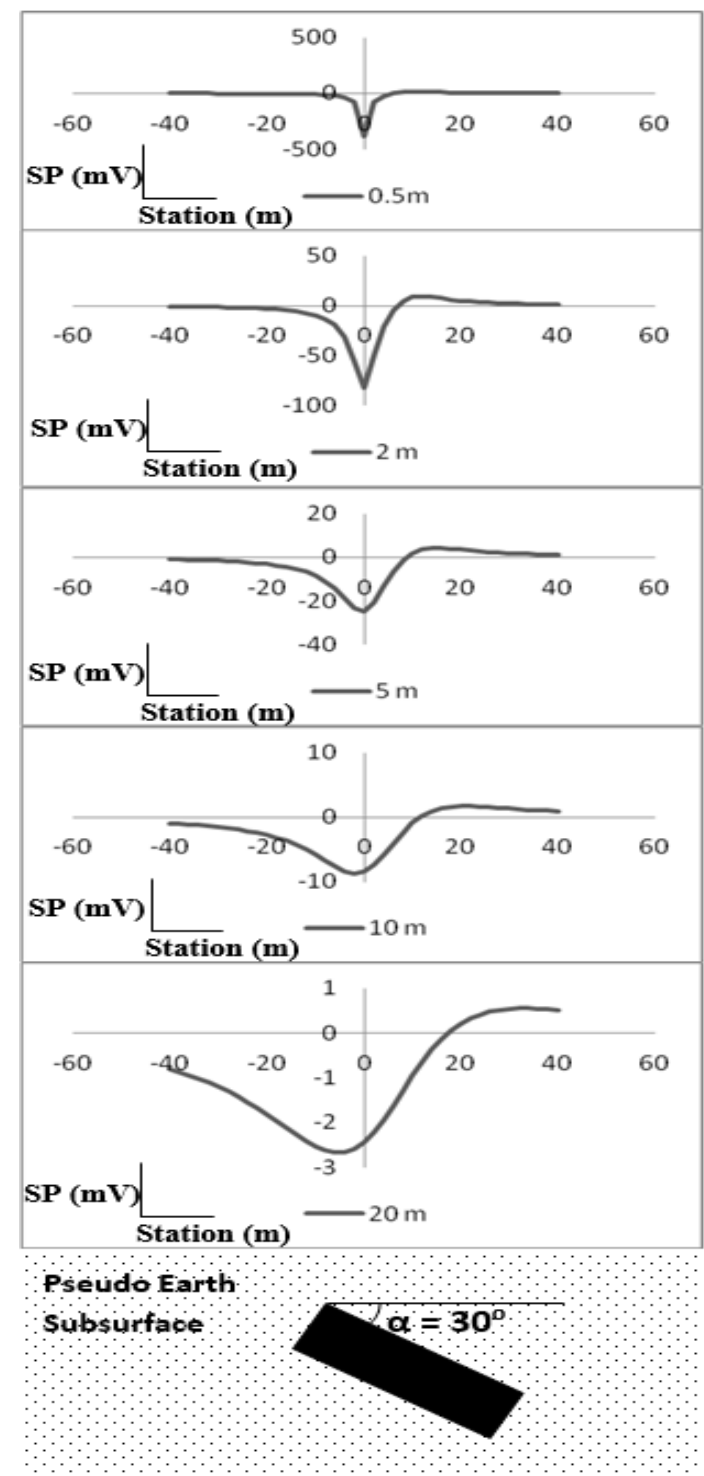

Figure 3: SP Profiles for $30^{\circ}$ Geologic Dip.

The superposition of SP anomaly curves of varying depth of burial with the same geologic dip show that, well pronounced negative amplitude is that of $0.5 \mathrm{~m}$ with SP value of $-380.03 \mathrm{mV}$. The average maximum SP value of negative amplitude is -380.58 $\mathrm{mV}$. Therefore, with same dip angle but varying depth of burial, the SP anomaly decreases in the peak negative amplitude as the depth of burial increased (Figures 6 -9). With same depth of burial but varying dip angle, the anomaly curves become asymmetrical with decreasing dip angle from $90^{\circ}$. Figures $7-9$ show the same signature as discussed by [2] of SP investigation, which revealed Weiss anomaly of the Maden copper mine, indicated that the source of signature could be spherical. It was established that vertically oriented pipe is associated with or characterized by relatively high-amplitude over the target [20] and this is not far fetch from this study.

However, at deeper depth $(>2.0 \mathrm{~m})$, the peak negative amplitude of the SP anomalies decreases in amplitude as dip angle is decreased from $90^{\circ}$ (Figures 12 and 13). The displacement 


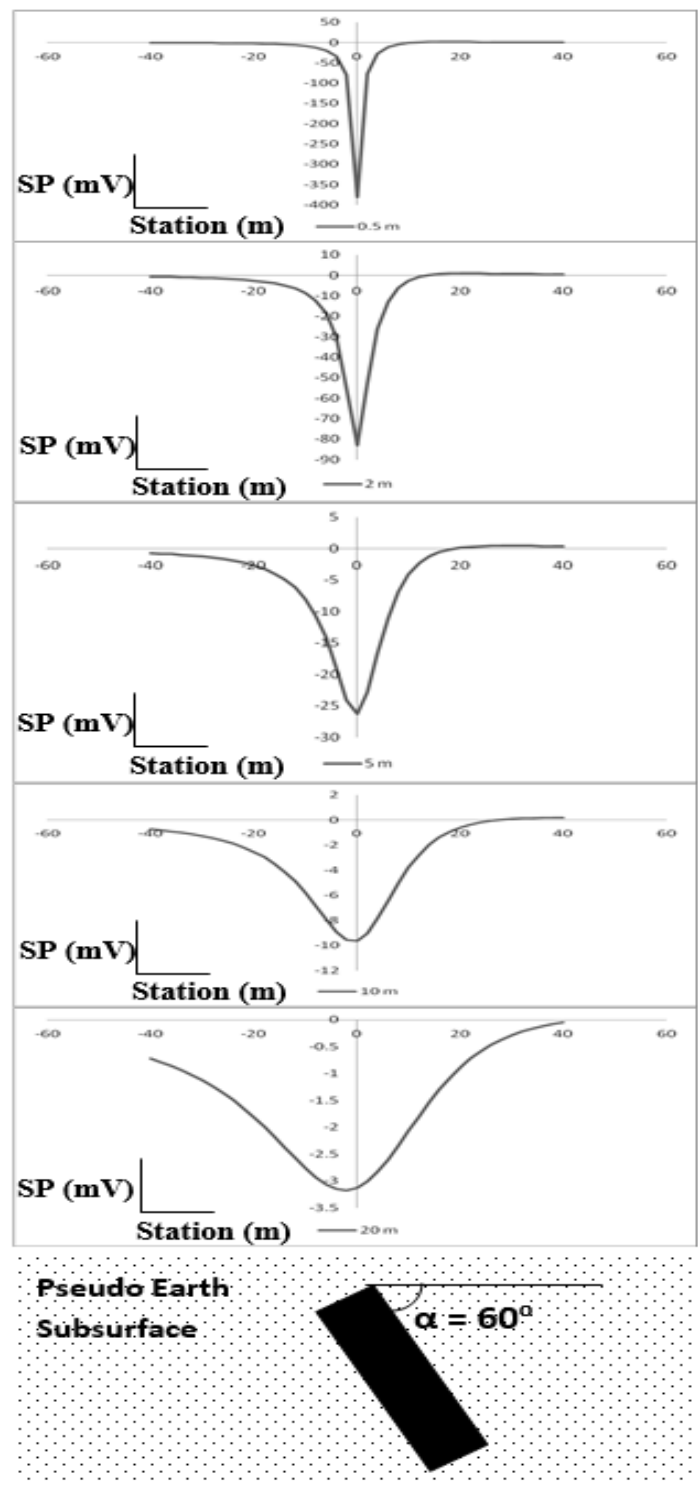

Figure 4: SP Profiles for $60^{\circ}$ Geologic Dip.

between the peak negative and peak positive of the SP anomalies generated at relatively shallow depth of burial $(<5.0 \mathrm{~m})$ is equal to the linear extent $(l)$ of the polarized rod or target.

\section{Conclusion}

The interpretation of SP anomaly curves shows that the inflection points of the anomaly curves are located at the middle of the rod for a polarized rod with $0^{\circ}$ dip. The displacement between the peak negative and positive amplitude of the SP anomalies is equal to the linear extent $(l)$ of the polarized rod or target of shallow depth of burial or zero dip. However, the SP anomaly decreases in the peak negative amplitude for fixed dip angle but increasing depth of burial. The anomaly curves become asymmetrical with decreasing dip angle from $90^{\circ}$ for fixed depth of burial and the anomalies for a vertically dipping rod is symmetrical about the top of target. In conclusion, depth of burial and geologic dip has great influence on the amplitude

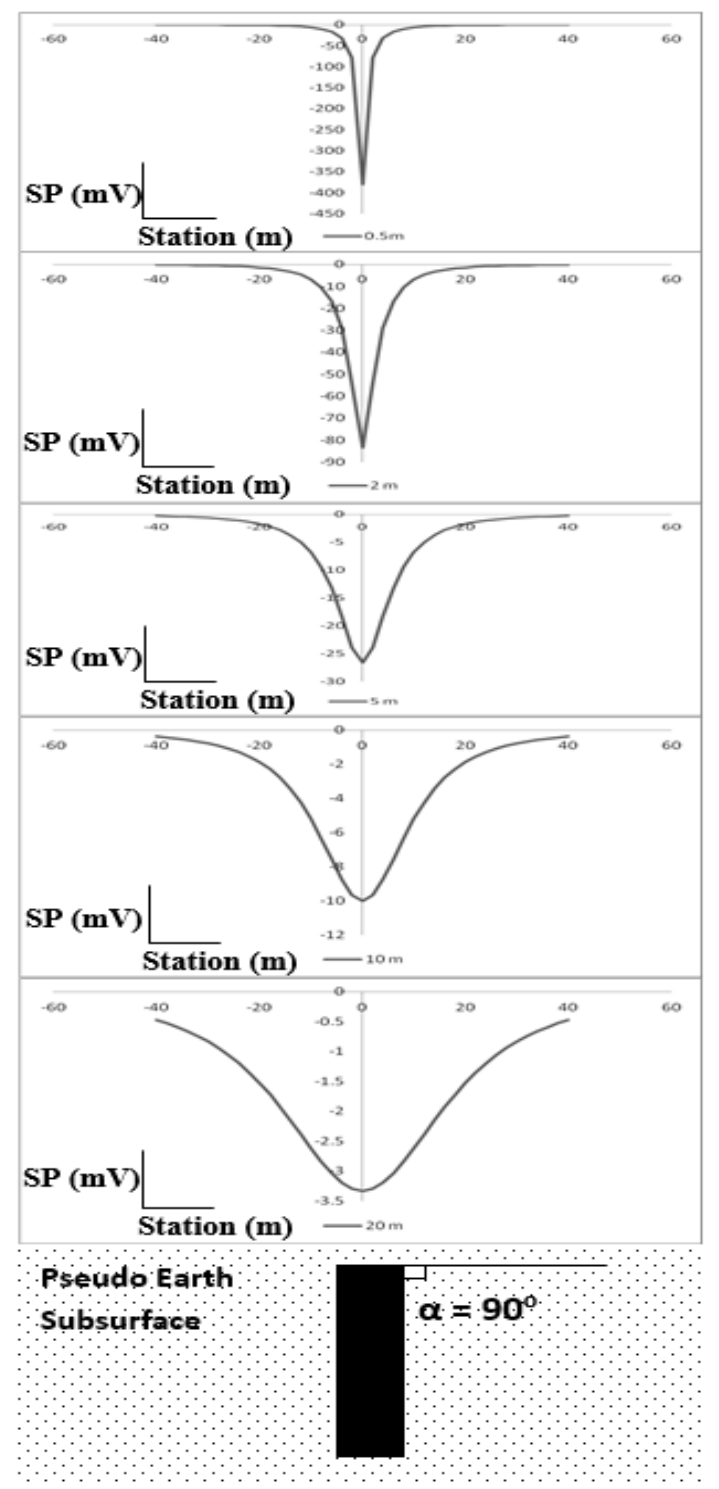

Figure 5: SP Profiles for $90^{\circ}$ Geologic Dip.

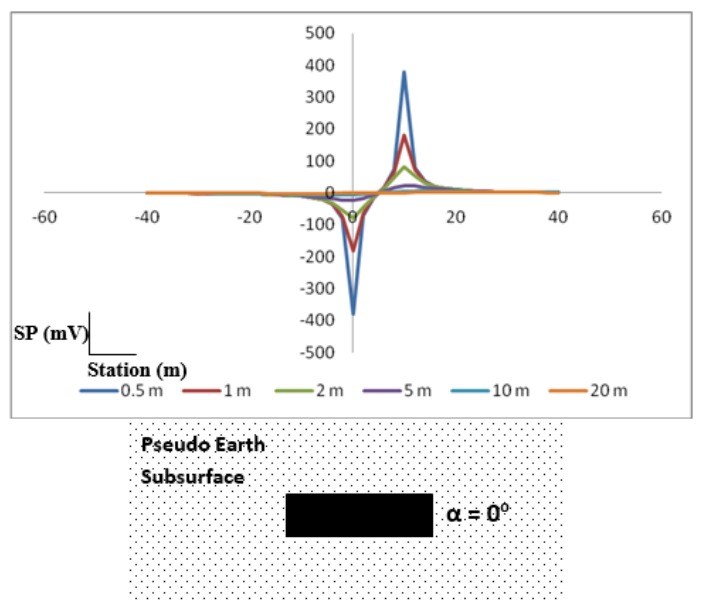

Figure 6: Superposition of SP Anomaly Curves for $0^{\circ}$ at Different Depth of Burial. 


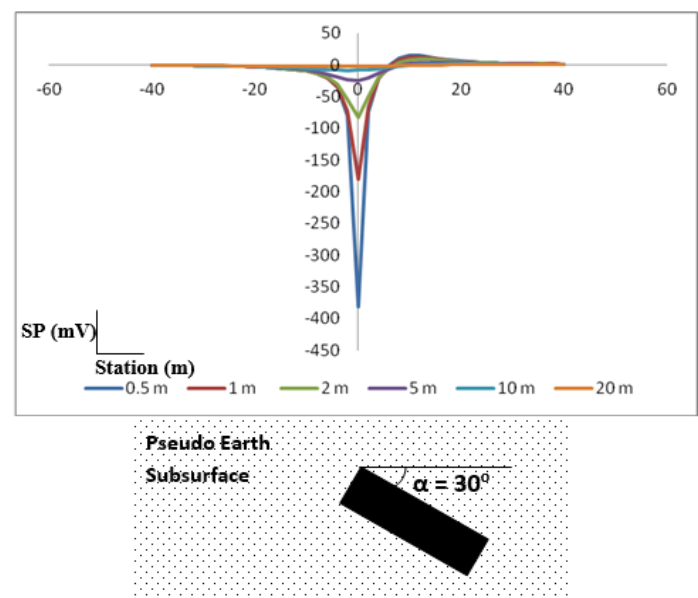

Figure 7: Superposition of SP Anomaly Curves for $30^{\circ}$ at Different Depth of Burial.

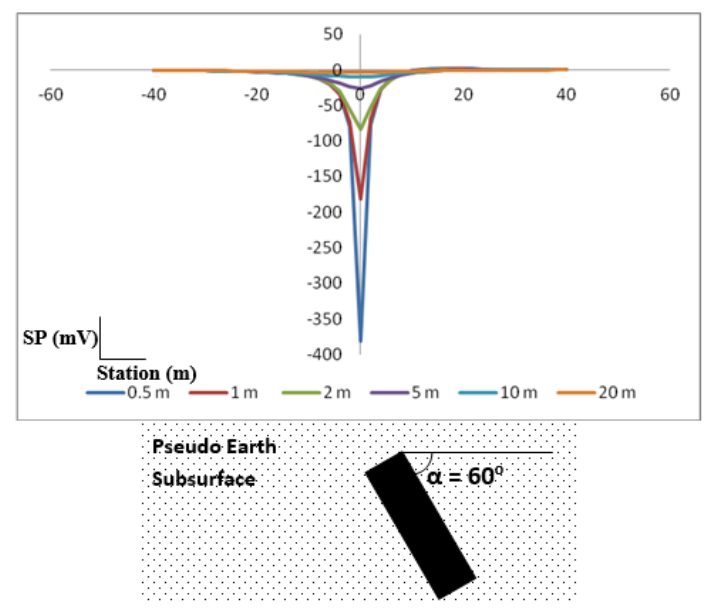

Figure 8: Superposition of SP Anomaly Curves for $60^{\circ}$ at Different Depth of Burial.

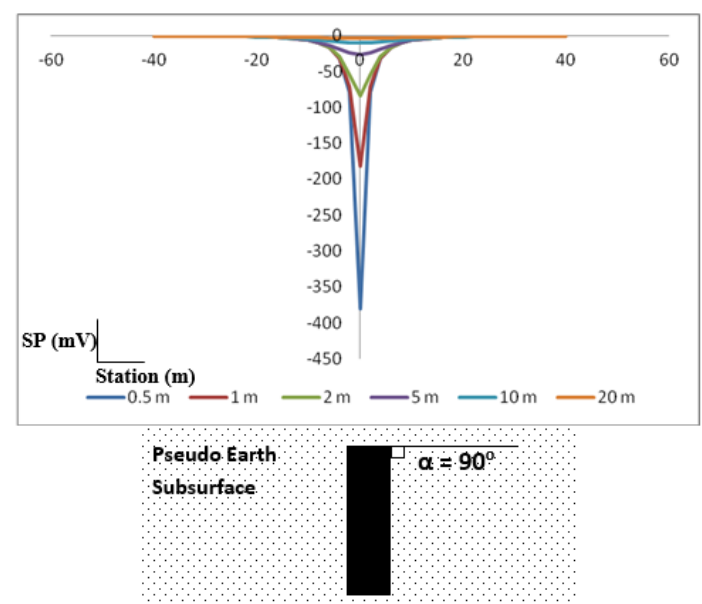

Figure 9: Superposition of SP Anomaly Curves for 90 at Different Depth of Burial.

and the symmetrical nature of self potential anomaly curve over an inclined object. Although numerical modeling is limited be-

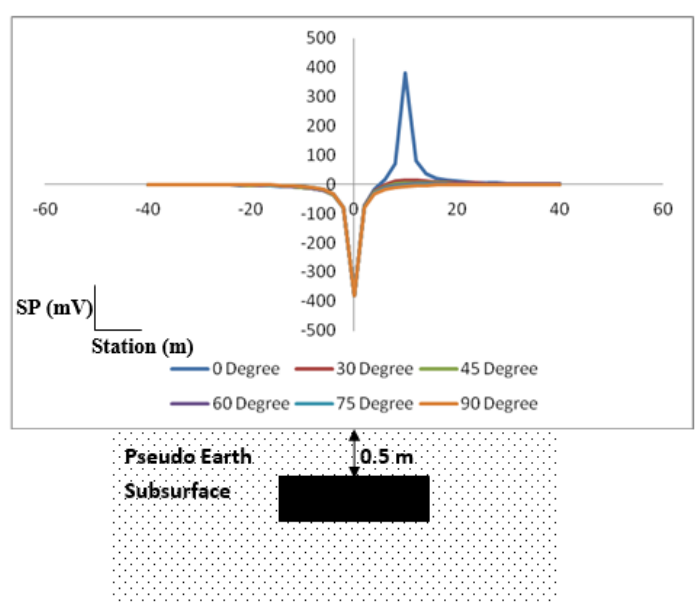

Figure 10: Superposition of SP Anomaly Curves for $0.5 \mathrm{~m}$ Depth of Burial at Different Dip.

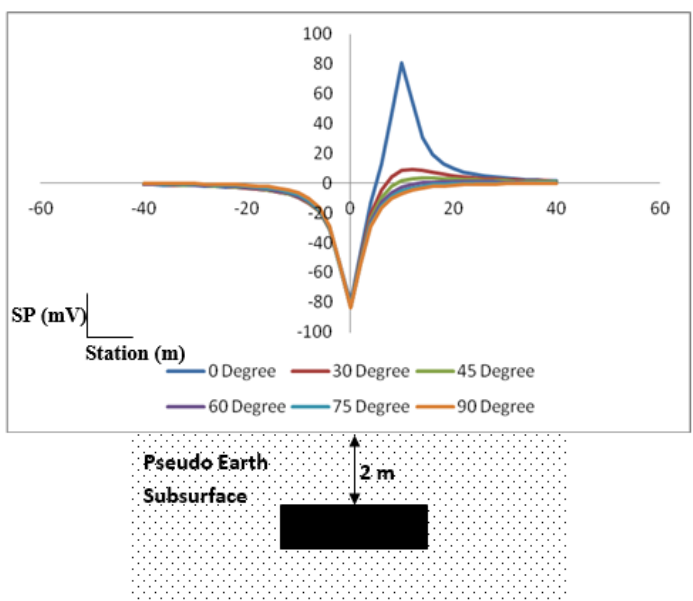

Figure 11: Superposition of SP Anomaly Curves for $2 m$ Depth of Burial at Different Dip.

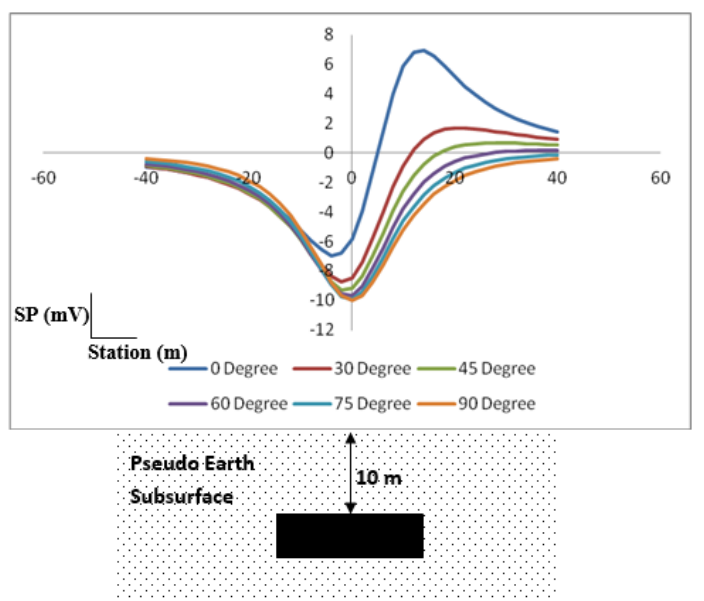

Figure 12: Superposition of SP Anomaly Curves for $10 \mathrm{~m}$ Depth of Burial at Different Dip.

cause of the interaction required on the field - it is assumed the earth material is isotropic and homogenous. Therefore, the lim- 


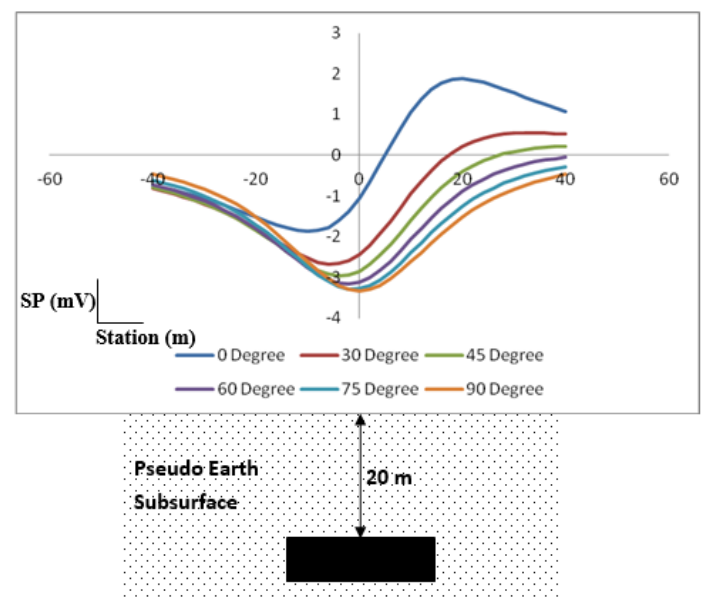

Figure 13: Superposition of SP Anomaly Curves for $20 \mathrm{~m}$ Depth of Burial at Different Dip.

itations of the numerical modeling are unable to account for the influence of the earths subsurface physical properties and environmental effects. Nonetheless, they still serve as frontier in exploration in geosciences as this study would serve as quality control on interpretation mindset of Geophysicists.

\section{Acknowledgments}

We appreciate Mr. O. A. Sanuade, Mr. J. O. Amosun and Dr. A. B. Eluwole for their advice and contributions towards the success of this work. We also thank the referees for the positive enlightening comments and suggestions, which have greatly helped us in making improvements to this paper

\section{References}

[1] A. Bokulich \& N. Oreskes, Models in the Geosciences. Handbook of Model-Based Science, 2017.

[2] M. E. Hesham, "A New Method for Complete Quantitative Interpretation of Self-Potential Anomalies", Journal of Applied Geophysics 55 (2004) 211.

[3] A. A. Adeyemi, A. I. Idornigie \& M. O. Olorunfemi, "Spontaneous Potential and Electrical Resistivity Response Modelling for a Thick Conducto", Journal of Applied Sciences Research textbf2 (2006) 691.

[4] I. Oliveti \& E. Cardarelli, "2D Approach for Modelling Self-Potential Anomalies: Application to Synthetic and Real Data", Bollettino di Geofisica Teorica ed Applicata 58 (2017) 415.
[5] J. M. Burke, "Modeling and Inversion of Self-Potential Data", Ph.D Thesis, Massachusetts Institute of Technology, United States of America, 2007.

[6] A. Crespy, A. Revil, N. Linde, S. Byrdina, A. Jardani, A. Bole 've \& P. Henry, "Detection and Localization of Hydromechanical Disturbances in a Sandbox Using the Self-Potential Method", Journal of Geophysical Research 113 (2007) 1.

[7] L. Alberto, "Application of Spontaneous Potential Profiles for Exploration of Goldrich Epithermal Low Sulphidation Veins in a Humid Region", Conference of Geological Society of South Africa in Johannesburg, July 8-16, 2004.

[8] V. E. Darwin \& M. S. Julian, "Well Logging for Earth Scientists”, Netherlands: Springer, 2007.

[9] H. H. Mohammed, R. S. Mohamed \& H. A. Wan, "Application of Well Log Analysis to Access the Petrophysical Parameters of the Lower Cretaceous Biyad Formation, East Shabowah Oilfields, Masila Basin, Yemen", World Applied Sciences Journal 16 (2012) 1227.

[10] M. O. Olorunfemi, A. I. Idornigie, H. O. Fagunloye \& O. A. Ogun, "Assessment of Anomalous Seepage Conditions in the Opa Dam Embankment, Ile Ife, SouthWestern Nigeria", Global Journal of Geological Sciences, 2 (2003) 991.

[11] P. Sjodahl, T. Dahlin \& S. Johansson, "Using the Resistivity Method for Leakage Detection in a Blind Test at the Rossvatn Embankment Dam Test Facility in Norway", Bulletin of Engineering Geology and the Environment 69 (2010) 643.

[12] N. Linde, J. Doetsch, D. Jougnot, O. Genoni, Y. Durst, B. J. Minsley, T. Vogt, N. Pasquale \& J. Luster, "Self-Potential Investigations of a Gravel Bar in a Restored River Corridor", Hydrology and Earth System Sciences 15 (2011) 729.

[13] G. Dominique, L. M. Jean-Louis, L. Luc, N. Florence \& P. Frederic, "Sap Flow and Daily Electric Potential Variations in a Tree Trunk, Remugol, France", Journal of Plant Sciences 171 (2006) 572.

[14] D. Jougnot, N. Linde, E. B. Haarder \& M. C. Looms, "Monitoring of Saline Tracer Movement with Vertically Distributed Self-Potential Measurements at the HOBE Agricultural Site, Voulund, Denmark", Journal of Hydrology 521 (2015) 314.

[15] W. C. Robert, Geotechnical Applications of the Self-Potential Method: Report 3: Development of Self-Potential Interpretation Techniques for Seepage Detection. US Army Corps of Engineers, Washington, DC, 1989.

[16] B. ÅogaÅa, M. J. Mendecki, W. M. Zuberek \& M. Robak, "Application of Self Potential Method in the Area Contaminated with Oil Derivatives", Acta Geodynamica et Geomaterialia 9 (2012) 179.

[17] P. Soupios \& M. Karaoulis, Application of Self-Potantial (SP) Method for Monitoring Contaminants Movement. 8th Congress of the Balkan Geophysical Society, Chania, Greece, 2015.

[18] W. M. Telford \& L. P. Geldart, Applied Geophysics. New York: Cambridge University Press, 1990.

[19] B. J. Dallas \& K. James, "Regional Self Potential Anomalies at Kilauea Volcano", US Geological Professional Paper 1350 (2016) 947.

[20] J. B. Rittgers, A. Revil, M. Karaoulis, M. A. Mooney, L. D. Slater \& E. A Atekwana, "Self-Potential Signals Generated by the Corrosion of Buried Metallic Objects with Application to Contaminant Plumes", Geophysics 78 (2013) 65 . 